\title{
Resistorless Current-Mode First-Order All-Pass Filter with Electronic Tuning Employing Low-Voltage CBTA and Grounded Capacitor*
}

\author{
Norbert Herencsar ${ }^{\dagger}$ and Jaroslav Koton ${ }^{\ddagger}$ \\ Department of Telecommunications \\ Brno University of Technology, Technicka 3082/12, 61600 Brno, Czech Republic \\ herencsn@feec.vutbr.cz \\ ${ }^{\ddagger}$ koton@feec.vutbr.cz \\ Abhirup Lahiri \\ D3-Friends Apartments, \\ IP Extension, Delhi, India \\ lahiriabhirup@yahoo.com \\ Umut E. Ayten \\ Department of Electronics and Communication Engineering, \\ Yildiz Technical University, Davutpasa Mah., 34220-Esenler, Istanbul, Turkey \\ ayten@yildiz.edu.tr \\ Mehmet Sagbas \\ Department of Electric-Electronics Engineering \\ Yeni Yuzyil University, 34010-Zeytinburnu, Istanbul, Turkey \\ sagbasm@gmail.com
}

Received (1 January 2017)

Revised (30 March 2017)

Accepted (25 May 2017)

In this paper, a new realization of a current-mode first-order all-pass filter (APF) using a single active building block $(\mathrm{ABB})$ and one grounded capacitor is presented. As the ABB, the current backward transconductance amplifier (CBTA) is used, which is one of the most recently reported active elements in the literature. The theoretical results are in detail verified by numerous SPICE simulations using a new low-voltage implementation of CBTA. In the design, the PTM $90 \mathrm{~nm}$ level-7 CMOS process BSIM3v3 parameters with $\pm 0.45 \mathrm{~V}$ supply voltages were used. The proposed resistorless CBTA-C APF provides easy electronic tuning of the pole frequency in frequency range from $763 \mathrm{kHz}$ to $17.6 \mathrm{MHz}$, which is more than one decade. Maximum power dissipation of the circuit is $828 \mu \mathrm{W}$ at bias current $233 \mu \mathrm{A}$. Non-ideal, parasitic effects, sensitivity analyses, temperature and noise variation, current swing capability, and Monte Carlo analysis results are also provided. Compared to prior state-of-the-art works, the proposed CBTA-C APF has achieved the highest Figure of Merit value, which proves its superior performance.

Keywords: All-pass filter; current-mode circuit; current backward transconductance amplifier; CBTA; first-order filter; FoM; low-voltage; grounded capacitor; tunable filter; resistorless circuit.

* This paper was recommended by Regional Editor...

${ }^{\dagger}$ Corresponding author.

Electronic version of an article published as Journal of Circuits, Systems and Computers, Vol. 27, No. 02, 1850031 (2018) DOI: https://doi.org/10.1142/S0218126618500317 


\section{Introduction}

First-order all-pass filters (APFs) are very important circuits for many analog signal processing applications. It is known that they are with advantage used for design of high$Q$ frequency-selective circuits, quadrature/multiphase oscillators, for phase equalization, and for frequency dependent delay design while keeping the amplitude of the output signal constant over the desired frequency range ${ }^{1}$. In general, the desired features for a current-mode (CM) APF can be the following:

(i) low impedance character of current input terminal, which is needed for easy cascading,

(ii) high output-impedance at current-mode output, which is required for direct load connection,

(iii) used capacitor is grounded, which is advantageous for monolithic integration,

(iv) no external resistor is used, i.e. circuit is resistorless,

(v) inherent electronic tuning of pole frequency is possible,

(vi) no passive and/or active matching constraints are required.

The recent surge in the interest of $\mathrm{CM}$ signal processing has led to large number of realizations of CM APFs using a variety of active building blocks (ABBs) ${ }^{2-46}$. Detailed comparison of these hitherto published CM APFs with here proposed one is given in Table 1. Among these filter topologies the realizations in Refs. 2-4 are based on bipolar junction transistors, employ dual-output current followers (DO-CFs), or DO-CFs in interconnection with adjustable current amplifier (ACA), respectively. In Ref. 5 two NMOS transistors, both operating in saturation region, forming inverting voltage buffer is used. Second-generation current conveyor $(\mathrm{CCII})^{6-12}$, second-generation currentcontrolled conveyor $(\mathrm{CCCII})^{13-20}$, dual-X second-generation multi-output current conveyor (DX-MOCCII $)^{21,22}$, third-generation current conveyor (CCIII) ${ }^{23,24}$, gain-variable third-generation current conveyor (GVCCIII) ${ }^{25}$, and differential voltage current conveyor $(\text { DVCC })^{26,27}$ were also very popular and useful ABBs for first-order APF design in the past. Later on, a four terminal floating nullor (FTFN) and voltage gain-controlled modified current feedback amplifier (VGC-MCFOA)-based CM APFs were introduced in the literature ${ }^{28,29}$. Operational transconductance amplifiers (OTAs) ${ }^{30,31}$ are also useful ABBs for APF design due to capability of pole frequency tuning. Current-mode APF employing current differencing buffered amplifier (CDBA) or current operational amplifier (COA) were published respectively in Refs. 32 and 33. During last decade the current differencing transconductance amplifier (CDTA) $)^{34-39}$ and its modification socalled current-differencing cascaded transconductance amplifier (CDCTA $)^{40}$ have also received significant attention. As it is known, the input circuitry of CDBA, COA, CDTA, and CDCTA forms the so-called current differencing unit (CDU), which was modified in Ref. 41 by considering current transfer gains and intrinsic input resistances in order to realize a $\mathrm{CM}$ APF. The z-copy current inverter/follower transconductance amplifiers (ZC-CITAs/ZC-CFTAs), which were employed in interesting CM $\mathrm{APFs}^{42,43}$ can be considered as slight simplification of CDTA, if omitting of $p$ or $n$ stage of input circuitry is assumed. The CM APF employing current controlled current conveyor 
transconductance amplifier (CCCCTA) fully enjoys the dual controllability of the used $\mathrm{ABB}^{44}$. The current-controllability feature of CFTA (CCCFTA) is with advantage used in Ref. 45. Finally, the CM APF reported in Ref. 46 employs current backward transconductance amplifier (CBTA), which is one of the most recently reported ABB in the literature.

In addition to the given study above our investigation also shows that the proposed circuits in Refs. 2-46 suffer from some additional weaknesses:

- use of BJTs in its internal structure $2,13-17,19,29,30,36-38,40,43-45$, which is not preferred due to effect of thermal voltage,

- use of multiple current output terminal ABB (device with three or more outputs) ${ }^{4,12,19,21,22,37,38,40,43}$, which increases the number of transistors in structure,

- employs excessive number of passive components (three or more) ${ }^{5-8,24-29,31,34,35,45}$,

- two or more capacitors are required $d^{5,26}$,

- capacitor is connected in series to low input-impedance terminal of $\mathrm{ABB}^{7,12,15,17,26,32-}$ 35,45 , and thus, their high frequency performances are limited,

- needs differential current input source ${ }^{4}$ or two input currents ${ }^{29}$,

- impractical CM APF realization in Refs. 17 and 45 since requiring one of the bias currents to be very large as compared to the other one,

- needs precise current transfer gain matching in used $\mathrm{ABB}^{13}$.

As conclusion, our deep literature survey available in Table 1 shows that the only circuits those having above listed desired features (i)-(vi) for a CM APF are available in Refs. 18-20, 38, 39, and 42-44. However, as our further study showed, internal structures of $^{19,38,43,44}$ employ BJTs, which are not preferred due to effect of thermal voltage. Moreover, use of multiple current output terminal ABB (device with three or more outputs) increases the number of transistors in structure on chip ${ }^{19,38,43}$. Therefore, realizations ${ }^{18,20,39,42}$ are by far the most appropriate CM APFs in the literature. Adding to the class of these circuits, in this paper new realization of CM APF using one of the most recently reported $\mathrm{ABB}$, namely the current backward transconductance amplifier $(\mathrm{CBTA})^{46-54}$ is proposed. In 2010, the CBTA was introduced as an active component to provide new possibilities in the circuit synthesis. Since that, the versatility of CBTA has been demonstrated in various analog signal processing applications. To the best of the authors' knowledge the only CBTA-based CM first-order APF exists in literature Ref. 46 so far, however, this realization is not resistorless and inherent electronic tuning of pole frequency is not possible due to matching constraint. Hence, circuit does not satisfy above listed desired features (iv)-(vi). Moreover, a new CMOS implementation of the CBTA using PTM $90 \mathrm{~nm}$ level-7 CMOS process BSIM3v3 parameters and with low supply voltages equal to $\pm 0.45 \mathrm{~V}$ is introduced. The workability of the proposed CBTA CMOS structure and resistorless CBTA-C CM APF is analyzed in detail using SPICE software. 
Table 1. Comparison of various CM all-pass filters.

\begin{tabular}{|c|c|c|c|c|c|c|}
\hline Reference $\backslash$ Feature & (i) & (ii) & (iii) & (iv) & (v) & (vi) \\
\hline Ref. 2 & no & yes & yes & yes & yes & yes \\
\hline Ref. 3 & yes & yes & yes & no & no & yes \\
\hline Ref. 4 & yes & yes & no & yes & yes & no \\
\hline Ref. 5 & no & no & no & no & no & no \\
\hline Ref. 6 & no & yes & no & no & no & no \\
\hline Ref. 7 & no & yes & yes & no & no & no \\
\hline Ref. 8 & no & yes & no & no & no & no \\
\hline Ref. 9 & yes & yes & yes & no & no & yes \\
\hline Ref. 10 & yes & yes & yes & no & no & yes \\
\hline Ref. 11 & yes & yes & yes & no & no & yes \\
\hline Ref. 12 & no & yes & yes & no & no & yes \\
\hline Ref. 13 & yes & yes & yes & yes & yes & no \\
\hline Ref. 14 in Figs. 1a,b & no & no & no & no & no & no \\
\hline Ref. 15 & no & yes & yes & yes & yes & no \\
\hline Ref. 16 & no & no & no & yes & yes & yes \\
\hline Ref. 17 & no & yes & no & yes & yes & no \\
\hline Ref. 18 & yes & yes & yes & yes & yes & yes \\
\hline Ref. 19 & yes & yes & yes & yes & yes & yes \\
\hline Ref. 20 & yes & yes & yes & yes & yes & yes \\
\hline Ref. 21 & yes & yes & yes & no & no & yes \\
\hline Ref. 22 & yes & yes & yes & no & no & yes \\
\hline Ref. 23 in Figs. $3 b, 4 b$ & no & no & no & no & no & yes \\
\hline Ref. 24 & no & yes & no & no & no & no \\
\hline Ref. 25 & no & no & yes & no & no & no \\
\hline Ref. 26 in Figs. 3 a, c, f & no & yes & no & no & no & no \\
\hline Ref. 27 & no & yes & yes & no & no & no \\
\hline Ref. 28 & no & no & yes & no & no & no \\
\hline Ref. 29 & no & yes & yes & no & yes & no \\
\hline Ref. 30 & no & no & no & yes & yes & yes \\
\hline Ref. 31 & no & yes & yes & no & no & no \\
\hline Ref. 32 & no & yes & no & no & no & yes \\
\hline Ref. 33 & no & yes & no & no & no & yes \\
\hline Ref. 34 & no & yes & no & no & no & yes \\
\hline Ref. 35 & no & yes & no & no & no & yes \\
\hline Ref. 36 & no & yes & no & yes & yes & yes \\
\hline Ref. 37 & no & yes & no & yes & yes & yes \\
\hline Ref. 38 & yes & yes & yes & yes & yes & yes \\
\hline Ref. 39 & yes & yes & yes & yes & yes & yes \\
\hline Ref. 40 & yes & yes & yes & no & yes & yes \\
\hline Ref. 41 & no & yes & no & yes & yes & yes \\
\hline Ref. 42 & yes & yes & yes & yes & yes & yes \\
\hline Ref. 43 & yes & yes & yes & yes & yes & yes \\
\hline Ref. 44 & yes & yes & yes & yes & yes & yes \\
\hline Ref. 45 & no & yes & no & no & yes & no \\
\hline Ref. 46 & yes & yes & yes & no & no & no \\
\hline This work & yes & yes & yes & yes & yes & yes \\
\hline
\end{tabular}




\section{Circuit Description}

\subsection{Description of the CBTA}

The circuit symbol of CBTA is shown in Fig. 1(a), where $p$ and $n$ are input terminals and $w, z-, z+$ are output terminals ${ }^{46-54}$. The equivalent circuit of the CBTA is shown in Fig. 1(b), which contains dependent current sources at $p, n, z-$, and $\mathrm{z}^{+}$terminals and voltage source at $w$ terminal. The terminal impedances for the ideal CBTA are infinite at $p, n, z-$, and $z+$ terminals and zero at $w$ terminal. Relations between the individual terminals of the CBTA can be described by the following hybrid matrix:

$$
\left[\begin{array}{c}
i_{\mathrm{p}} \\
i_{\mathrm{n}} \\
v_{\mathrm{w}} \\
i_{\mathrm{z}-} \\
i_{\mathrm{z}+}
\end{array}\right]=\left[\begin{array}{ccccc}
0 & 0 & \alpha_{\mathrm{p}}(s) & 0 & 0 \\
0 & 0 & -\alpha_{\mathrm{n}}(s) & 0 & 0 \\
0 & 0 & 0 & 0 & \mu_{\mathrm{w}}(s) \\
-g_{\mathrm{m}}(s) & g_{\mathrm{m}}(s) & 0 & 0 & 0 \\
g_{\mathrm{m}}(s) & -g_{\mathrm{m}}(s) & 0 & 0 & 0
\end{array}\right]\left[\begin{array}{c}
v_{\mathrm{p}} \\
v_{\mathrm{n}} \\
i_{\mathrm{w}} \\
v_{\mathrm{z}-} \\
v_{\mathrm{z}+}
\end{array}\right] .
$$

Here, $\alpha_{\mathrm{p}}(s), \alpha_{\mathrm{n}}(s)$, and $\mu_{\mathrm{w}}(s)$ are respectively the current and voltage gains and they can be expressed as $\alpha_{\mathrm{p}}(s)=\omega_{\alpha \mathrm{p}}\left(1-\varepsilon_{\alpha \mathrm{p}}\right) /\left(s+\omega_{\alpha \mathrm{p}}\right), \quad \alpha_{\mathrm{n}}(s)=\omega_{\alpha \mathrm{n}}\left(1-\varepsilon_{\alpha \mathrm{n}}\right) /\left(s+\omega_{\alpha \mathrm{n}}\right)$, $\mu_{\mathrm{w}}(s)=\omega_{\mu \mathrm{w}}\left(1-\varepsilon_{\mu \mathrm{w}}\right) /\left(s+\omega_{\mu \mathrm{w}}\right) \quad$ with $\left|\varepsilon_{\alpha \mathrm{p}}\right| \ll 1, \quad\left|\varepsilon_{\alpha \mathrm{n}}\right| \ll 1$, and $\left|\varepsilon_{\mu \mathrm{w}}\right| \ll 1$. In addition, $g_{\mathrm{m}}(s)=g_{\mathrm{o}} \omega_{\mathrm{gm}}\left(1-\varepsilon_{g \mathrm{~m}}\right) /\left(s+\omega_{\mathrm{gm}}\right)$, where $\left|\varepsilon_{\mathrm{gm}}\right| \ll 1$. The $g_{\mathrm{o}}$ is the DC transconductance gain, $\varepsilon_{\alpha \mathrm{p}}$ and $\varepsilon_{\alpha \mathrm{n}}$ denote the current tracking errors, $\varepsilon_{\mu \mathrm{w}}$ denotes the voltage tracking error, $\varepsilon_{g \mathrm{~m}}$ denotes the transconductance error while $\omega_{\alpha \mathrm{p}}, \omega_{\alpha \mathrm{n}}, \omega_{\mu \mathrm{w}}, \omega_{g \mathrm{~m}}$ denote corresponding corner frequencies. Note that in the ideal case, the current and voltage gains are unity i.e. $\alpha_{\mathrm{p}}(s)=\alpha_{\mathrm{n}}(s)=1, \mu_{\mathrm{w}}(s)=1$ and frequency independent.

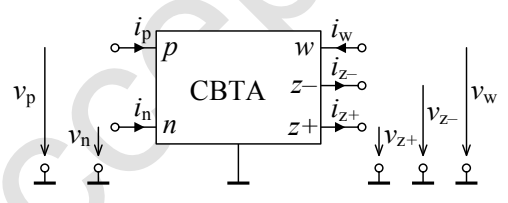

(a)

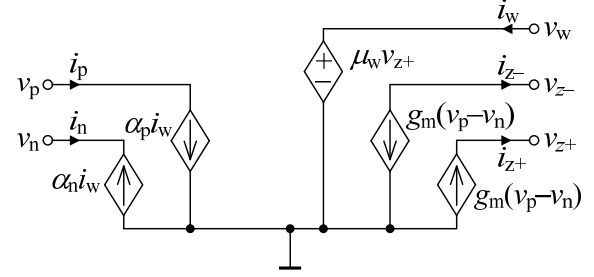

(b)

Fig. 1. (a) Circuit symbol of CBTA, (b) equivalent circuit of the CBTA.

The proposed low-voltage CMOS implementation of the CBTA is given in Fig. 2. The dimensions of the MOS transistors used in the CBTA implementation are listed in Table 2. In Fig. 2, transistors $\mathrm{M}_{1}-\mathrm{M}_{14}$ form a current conveyor and the transistors $\mathrm{M}_{21}-$ $\mathrm{M}_{32}$ are used for realizing the transconductance section. In addition, transistors $\mathrm{M}_{15}$ $\mathrm{M}_{20}$ are employed for biasing. Assuming that the output resistances of the transistors $\mathrm{M}_{1}-\mathrm{M}_{4}$ being equal to $r_{\mathrm{o}}$, the resistances seen at input and output terminals of the CBTA at mid-frequency region can be found as follows: 


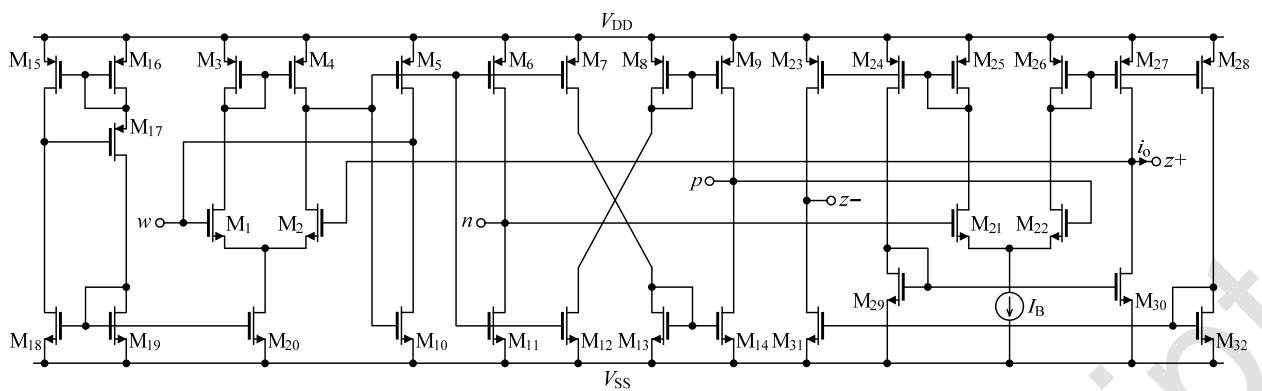

Fig. 2. Proposed low-voltage CMOS implementation of CBTA.

Table 2. Transistor dimensions of the CBTA in Fig. 2.

\begin{tabular}{cc}
\hline PMOS Transistors & $\mathrm{W}(\mu \mathrm{m}) / \mathrm{L}(\mu \mathrm{m})$ \\
\hline $\mathrm{M}_{3}, \mathrm{M}_{4}$ & $14.4 / 0.36$ \\
$\mathrm{M}_{5}-\mathrm{M}_{9}$ & $28.8 / 0.36$ \\
$\mathrm{M}_{15}$ & $0.36 / 0.09$ \\
$\mathrm{M}_{16}, \mathrm{M}_{17}$ & $1.8 / 0.09$ \\
$\mathrm{M}_{23}-\mathrm{M}_{28}$ & $5.76 / 0.18$ \\
\hline $\mathrm{NMOS} \mathrm{Transistors}_{1}, \mathrm{M}_{2}(\mu \mathrm{m}) / \mathrm{L}(\mu \mathrm{m})$ \\
\hline $\mathrm{M}_{10}-\mathrm{M}_{14}$ & $7.2 / 0.36$ \\
$\mathrm{M}_{18}, \mathrm{M}_{19}$ & $6.66 / 0.36$ \\
$\mathrm{M}_{20}$ & $0.72 / 0.09$ \\
$\mathrm{M}_{21}, \mathrm{M}_{22}, \mathrm{M}_{29}-\mathrm{M}_{32}$ & $3.24 / 0.09$ \\
\hline
\end{tabular}

$$
R_{\mathrm{p}}=\frac{r_{\mathrm{o} 9} r_{\mathrm{o} 14}}{r_{\mathrm{o} 9}+r_{\mathrm{o} 14}}
$$

$$
R_{\mathrm{n}}=\frac{r_{\mathrm{o} 6} r_{\mathrm{o} 11}}{r_{\mathrm{o} 6}+r_{\mathrm{o} 11}}
$$

$$
R_{\mathrm{w}}=\frac{1}{\frac{r_{\mathrm{o} 5}+r_{\mathrm{o} 10}}{r_{\mathrm{o} 5} r_{\mathrm{o} 10}}+g_{\mathrm{m} 1} \frac{r_{\mathrm{o}}}{2}\left(g_{\mathrm{m} 5}+g_{\mathrm{m} 10}\right)} \cong \frac{2}{g_{\mathrm{m} 1} r_{\mathrm{o}}\left(g_{\mathrm{m} 5}+g_{\mathrm{m} 10}\right)},
$$

$$
\begin{aligned}
& R_{\mathrm{z}-}=\frac{r_{023} r_{031}}{r_{\mathrm{o} 23}+r_{031}}, \\
& R_{\mathrm{z}+}=\frac{r_{027} r_{030}}{r_{027}+r_{030}},
\end{aligned}
$$

where $r_{\mathrm{o} i}$ and $g_{\mathrm{m} i}$ is the output resistance and transconductance of the $i$-th CMOS transistor, respectively.

In the transconductance section we will assume that all MOS devices operate in the saturation region. Let us also assume that $\mathrm{M}_{21}$ and $\mathrm{M}_{22}$ are perfectly matched and the current mirrors have unity current gain. Then the output current $i_{o}$ can be given by: 


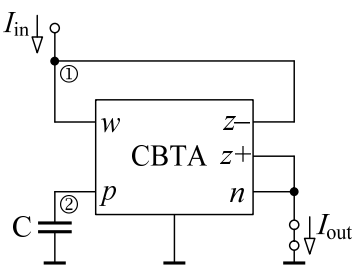

Fig. 3. Proposed CBTA-C current-mode first-order all-pass filter.

$$
i_{\mathrm{o}}=g_{\mathrm{m}} v_{\mathrm{in}}=\left(\sqrt{2 I_{\mathrm{B}} K}\right) v_{\mathrm{in}},
$$

where $v_{\text {in }}$ is the differential input voltage $\left(v_{\mathrm{in}}=v_{\mathrm{p}}-v_{\mathrm{n}}\right), I_{\mathrm{B}}$ is the bias current, $K=\mu C_{\mathrm{OX}} W / 2 L$ is the transconductance parameter, $\mu$ is carrier mobility, $C_{\mathrm{OX}}$ is the gateoxide capacitance per unit area, $W$ is the effective channel width, and $L$ is the effective channel length of $\mathrm{M}_{21}$ and $\mathrm{M}_{22}$ transistors, respectively.

\subsection{Proposed novel filter configuration}

The proposed CM CBTA-C first-order APF is shown in Fig. 3. It consists of a single CBTA and a grounded capacitor. Hence, the proposed circuit is desirable for monolithic integration. Assuming an ideal CBTA i.e. $\alpha_{\mathrm{p}}(s)=\alpha_{\mathrm{n}}(s)=1$ and $\mu_{\mathrm{w}}(s)=1$, routine circuit analysis yields the following transfer function (TF):

$$
T(s)=\frac{I_{\text {out }}}{I_{\text {in }}}=\frac{s C-g_{\mathrm{m}}}{s C+g_{\mathrm{m}}}=\frac{s C-\sqrt{2 I_{\mathrm{B}} K}}{s C+\sqrt{2 I_{\mathrm{B}} K}} .
$$

From Eq. (4), the phase of the filter is found as:

$$
\varphi(\omega)=180^{\circ}-2 \tan ^{-1}\left(\frac{\omega C}{g_{\mathrm{m}}}\right)=180^{\circ}-2 \tan ^{-1}\left(\frac{\omega C}{\sqrt{2 I_{\mathrm{B}} K}}\right),
$$

hence, from the Eq. (5) it can be seen that the proposed configuration can provide phase shifting between $180^{\circ}$ (at $\omega=0$ ) to $0^{\circ}$ (at $\omega=\infty$ ) by means of the transconductance, i.e. bias current $I_{\mathrm{B}}$ of CBTA.

Finally, the zero $\left(\omega_{z}\right)$ and pole $\left(\omega_{\mathrm{p}}\right)$ frequencies from TF in (4) can be calculated as:

$$
\omega_{\mathrm{z}}=\omega_{\mathrm{p}}=\frac{g_{\mathrm{m}}}{C}=\frac{\sqrt{2 I_{\mathrm{B}} K}}{C},
$$

and their sensitivities to passive element and active parameter are given as follows:

$$
S_{g_{\mathrm{m}}}^{\omega_{z}, \omega_{\mathrm{p}}}=-S_{C}^{\omega_{z} \omega_{\mathrm{p}}}=1,
$$

and are unity in relative amplitude. 


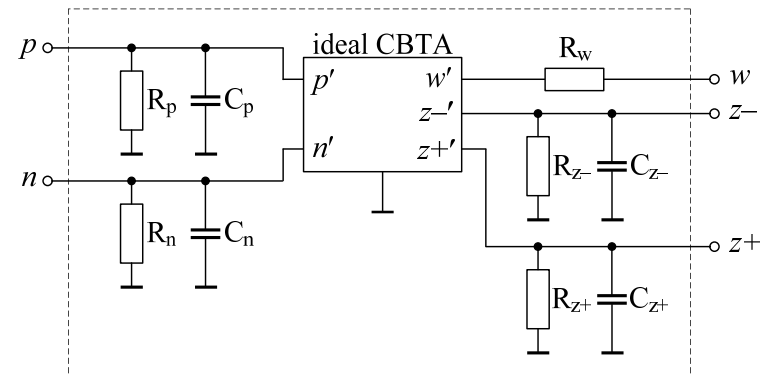

Fig. 4. Parasitic resistance and capacitance of the CBTA.

\subsection{Non-ideal and parasitic effects analysis}

For a complete analysis it is important to take into account parasitic resistances and capacitances of the used active element shown in Fig. 4. Therefore, considering these non-idealities, the matrix relationship in (1) changes to a form:

$$
\left[\begin{array}{c}
i_{\mathrm{p}} \\
i_{\mathrm{n}} \\
v_{\mathrm{w}} \\
i_{\mathrm{z}-} \\
i_{\mathrm{z}+}
\end{array}\right]=\left[\begin{array}{ccccc}
s C_{\mathrm{p}}+1 / R_{\mathrm{p}} & 0 & \alpha_{\mathrm{p}}(s) & 0 & 0 \\
0 & s C_{\mathrm{n}}+1 / R_{\mathrm{n}} & -\alpha_{\mathrm{n}}(s) & 0 & 0 \\
0 & 0 & R_{\mathrm{w}} & 0 & \mu_{\mathrm{w}}(s) \\
-g_{\mathrm{m}}(s) & g_{\mathrm{m}}(s) & 0 & s C_{\mathrm{z}-}+1 / R_{\mathrm{z}-} & 0 \\
g_{\mathrm{m}}(s) & -g_{\mathrm{m}}(s) & 0 & 0 & s C_{\mathrm{z}+}+1 / R_{\mathrm{z}+}
\end{array}\right]\left[\begin{array}{c}
v_{\mathrm{p}} \\
v_{\mathrm{n}} \\
i_{\mathrm{w}} \\
v_{\mathrm{z}-} \\
v_{\mathrm{z}+}
\end{array}\right],
$$

in which:

- the parasitic resistances $R_{\mathrm{p}}, R_{\mathrm{n}}$ and parasitic capacitances $C_{\mathrm{p}}, C_{\mathrm{n}}$ appear between the high-impedance $p$ and $n$ input terminals of the CBTA and ground, respectively, and their values for the implementation shown in Fig. 2 computed in SPICE software are $191.504 \mathrm{k} \Omega \| 41.12 \mathrm{fF}$ and $182.392 \mathrm{k} \Omega \| 8.43 \mathrm{pF}$, respectively,

- the parasitic resistances $R_{\mathrm{z}-}, R_{\mathrm{z}^{+}}$and parasitic capacitances $C_{\mathrm{z}-}, C_{\mathrm{z}^{+}}$appear between the high-impedance $z-$ and $z^{+}$output terminals of the CBTA and ground, respectively, and their values are $95.75 \mathrm{k} \Omega \| 9.21 \mathrm{fF}$ and $95.75 \mathrm{k} \Omega \| 25.81 \mathrm{fF}$, respectively,

- the non-zero parasitic resistance $R_{\mathrm{w}}$ at output terminal $w$ has the value $6.65 \Omega$.

Hence, for the proposed APF shown in Fig. 3 the following parasitic resistances and capacitances should be considered:

- $\quad$ parasitic impedances at the node (1) are equal to $Z_{\mathrm{w}}=R_{\mathrm{w}}$ and $Z_{\mathrm{z}^{-}}=R_{\mathrm{z}-} \|\left(1 / s C_{\mathrm{z}-}\right)$,

- parasitic impedance at the node (2) is $Z_{\mathrm{p}}=R_{\mathrm{p}} \|\left(1 / s C_{\mathrm{p}}\right)$. Note that the capacitance $C_{\mathrm{p}}$ can be absorbed into external capacitor $C$ as it appears in parallel with it. In analysis the total capacitance at this node will be labeled as $C^{\prime}$.

Therefore, taking into account the non-ideal current and voltage gains of the CBTA and simultaneously effect of aforementioned non-idealities and re-analyzing the proposed APF shown in Fig. 3, the ideal TF in Eq. (4) converts to: 


$$
T^{\prime}(s)=\frac{I_{\text {out }}}{I_{\text {in }}}=\frac{Z_{\mathrm{z}-}\left(\alpha_{\mathrm{p}} Z_{\mathrm{p}} s C^{\prime}+\alpha_{\mathrm{p}}-\alpha_{\mathrm{n}} g_{\mathrm{m}} Z_{\mathrm{p}}\right)}{Z_{\mathrm{p}} s C^{\prime}\left(Z_{\mathrm{z}-}+Z_{\mathrm{w}}\right)+Z_{\mathrm{z}-}\left(\alpha_{\mathrm{n}} g_{\mathrm{m}} Z_{\mathrm{p}}+1\right)+Z_{\mathrm{w}}} .
$$

Now, the non-ideal phase response of the filter from TF (9) can be expressed as:

$$
\varphi^{\prime}(\omega)=180^{\circ}-\tan ^{-1}\left(\omega C^{\prime} \frac{\alpha_{\mathrm{p}} Z_{\mathrm{p}}}{\alpha_{\mathrm{p}}-\alpha_{\mathrm{n}} g_{\mathrm{m}} Z_{\mathrm{p}}}\right)-\tan ^{-1}\left(\omega C^{\prime} \frac{Z_{\mathrm{p}}\left(Z_{\mathrm{z}-}+Z_{\mathrm{w}}\right)}{Z_{\mathrm{z}-}\left(\alpha_{\mathrm{n}} g_{\mathrm{m}} Z_{\mathrm{p}}+1\right)+Z_{\mathrm{w}}}\right) .
$$

Subsequently, it can be seen that the zero $\omega_{\mathrm{z}}$ and pole $\omega_{\mathrm{p}}$ frequencies differ and can be given as:

$$
\begin{gathered}
\omega_{\mathrm{z}}^{\prime}=\frac{\alpha_{\mathrm{p}}-\alpha_{\mathrm{n}} g_{\mathrm{m}} Z_{\mathrm{p}}}{\alpha_{\mathrm{p}} Z_{\mathrm{p}} C^{\prime}}, \\
\omega_{\mathrm{p}}^{\prime}=\frac{Z_{\mathrm{z}-}\left(\alpha_{\mathrm{n}} g_{\mathrm{m}} Z_{\mathrm{p}}+1\right)+Z_{\mathrm{w}}}{Z_{\mathrm{p}} C^{\prime}\left(Z_{\mathrm{z}-}+Z_{\mathrm{w}}\right)} .
\end{gathered}
$$

However, note that the effect of non-ideal gains and parasitics can be minimized by:

(i) making the $\alpha_{\mathrm{p}}, \alpha_{\mathrm{n}}$, and $\mu_{\mathrm{w}}$ very close to unity and/or,

(ii) providing precise design of the transconductance $g_{\mathrm{m}}$ section and/or,

(iii) reducing the non-zero parasitic impedance at output terminal $w$ by precise design of the current conveyor section or by connecting to negative impedance converter such that $Z_{\mathrm{w}} \approx 0$ and/or,

(iv) choosing $g_{\mathrm{m}} \gg 1 / Z_{\mathrm{p}}$ and $g_{\mathrm{m}} \gg 1 / Z_{\mathrm{z}-}$.

\section{Simulation Results and Performance Comparison}

To prove the theory, the performance of the proposed low-voltage CBTA implementation shown in Fig. 2 and new APF from Fig. 3 have been verified by SPICE simulations with DC power supply voltages equal to $+V_{\mathrm{DD}}=-V_{\mathrm{SS}}=0.45 \mathrm{~V}$. In the design transistors were modeled by the Predictive Technology Model (PTM) $90 \mathrm{~nm}$ level-7 CMOS process BSIM3v3 parameters of the Nanoscale Integration and Modeling (NIMO) Group at Arizona State University $\left(V_{\mathrm{TN} 0}=0.2607 \mathrm{~V}, \quad \mu_{\mathrm{N}}=0.017999999 \mathrm{~cm}^{2} /(\mathrm{V} \cdot \mathrm{s})\right.$, $\left.V_{\mathrm{TP} 0}=-0.303 \mathrm{~V}, \mu_{\mathrm{P}}=0.0055 \mathrm{~cm}^{2} /(\mathrm{V} \cdot \mathrm{s}), T_{\mathrm{OX}}=2.5 \mathrm{~nm}\right)^{55}$. The dimensions of the MOS transistors in the CBTA structure are given in Table 2. All the simulations were provided by setting temperature default $27^{\circ} \mathrm{C}$.

\subsection{CBTA behavior verification}

First of all, the behavior of the CBTA was tested by AC analyses. During simulations the biasing current $I_{\mathrm{B}}$ was set for $63 \mu \mathrm{A}$, which results transconductance gain $g_{\mathrm{m}}$ equal to $501.5 \mu \mathrm{A} / \mathrm{V}$. Due to the non-idealities of the CBTA, some discrepancies exhibit between theory and simulations. As a result, corner frequencies were found to be $\omega_{\alpha \mathrm{p}}=3884 \mathrm{Mrad} / \mathrm{s}, \omega_{\alpha \mathrm{n}}=4212 \mathrm{Mrad} / \mathrm{s}, \omega_{\mu \mathrm{w}}=4751 \mathrm{Mrad} / \mathrm{s}$, and $\omega_{\mathrm{gm}}=7741 \mathrm{Mrad} / \mathrm{s}$ and 
errors of these gains are $\varepsilon_{\alpha \mathrm{p}}=0.009, \varepsilon_{\alpha \mathrm{n}}=0.000, \varepsilon_{\mu \mathrm{w}}=-0.004$, and $\varepsilon_{g \mathrm{~m}}=0.018$. For lowfrequency region $\alpha_{\mathrm{p}}, \alpha_{\mathrm{n}}, \mu_{\mathrm{w}}$, and $g_{\mathrm{m}}$ can be assumed to be the constants with values $1-\varepsilon_{\alpha \mathrm{p}}=0.991,1-\varepsilon_{\alpha \mathrm{n}}=1,1-\varepsilon_{\mu \mathrm{w}}=1.004$, and $1-\varepsilon_{g \mathrm{~m}}=-0.003$, respectively, and $g_{\mathrm{o}}=500 \mu \mathrm{A} / \mathrm{V}$. Hence, the maximum operating frequency of the CBTA is $f_{\text {max }}=\min \left\{f_{\alpha \mathrm{p}}, f_{\alpha \mathrm{an}}, f_{\mu \mathrm{w}}, f_{\mathrm{gm}}\right\} \approx 618.1 \mathrm{MHz}$.

The SPICE simulations also showed that the value of the transconductance gain $g_{\mathrm{m}}$ of the CBTA can be varied between $38 \mu \mathrm{A} / \mathrm{V}$ and $880 \mu \mathrm{A} / \mathrm{V}$ by tuning the current $I_{\mathrm{B}}$ between $3 \mu \mathrm{A}$ and $233 \mu \mathrm{A}$, respectively. Therefore, as a consequence, the total power dissipation (TPD) of the CBTA changes from $221 \mu \mathrm{W}$ to $828 \mu \mathrm{W}$.

In addition, the DC analysis of the CMOS CBTA implementation given in Fig. 2 was also investigated. For simulating the DC transconductance transfer of $i_{z \pm}$ against $v_{\mathrm{p}}-v_{\mathrm{n}}$ when $g_{\mathrm{m}}=501.5 \mu \mathrm{A} / \mathrm{V}$, and DC voltage transfer of $v_{\mathrm{w}}$ against $v_{\mathrm{z}^{+}}$were performed by applying DC voltage sweep between $-0.45 \mathrm{~V} \leq\left(v_{\mathrm{p}}-v_{\mathrm{n}}\right) \leq 0.45 \mathrm{~V}$ to the $p$ and $n$ terminals of the CBTA. The output $z \pm$ terminal currents were measured while $1 \mathrm{~T} \Omega$ resistor was connected to the $w$ output of the CBTA and the output $z \pm$ terminals were grounded. As a result, the CBTA works linearly between $-49 \mu \mathrm{A} \leq i_{z \pm} \leq 49 \mu \mathrm{A}$ and $-60 \mathrm{mV} \leq v_{\mathrm{p}}-v_{\mathrm{n}} \leq 60 \mathrm{mV}$. In simulation of voltage transfer of $v_{\mathrm{w}}$ against $v_{\mathrm{z}+}$, a DC voltage sweep between $-0.45 \mathrm{~V} \leq v_{z^{+}} \leq 0.45 \mathrm{~V}$ was applied to the $z^{+}$terminal of the CBTA. The output $w$ terminal voltage was measured while $1 \mathrm{~T} \Omega$ resistor was connected to the $w$ output of the CBTA and the $p$ and $n$ terminals were grounded. As a result, the CBTA works linearly between $-0.45 \mathrm{~V} \leq v_{w} \leq 0.32 \mathrm{~V}$. The DC current transfer characteristics of $i_{\mathrm{p}}$ and $i_{\mathrm{n}}$ against $i_{\mathrm{w}}$ for the proposed CBTA were obtained by applying DC current sweep between $-1 \mathrm{~mA} \leq i_{\mathrm{w}} \leq 1 \mathrm{~mA}$ to the $w$ terminal of the CBTA. The input $p$ and $n$ terminal currents were measured while the $z, p$, and $n$ terminals were connected to ground. As a result, the CBTA works linearly between $-300 \mu \mathrm{A} \leq i_{\mathrm{p}} \leq 280 \mu \mathrm{A}$ and $-700 \mu \mathrm{A} \leq i_{\mathrm{n}} \leq 680 \mu \mathrm{A}$.

\subsection{Filter topology verification}

The proposed CM APF given in Fig. 3 has been analyzed using the designed CMOS implementation of the CBTA in SPICE software. In all simulations the value of the capacitor $C$ has been selected as $7.8 \mathrm{pF}$. Note that, as it was in the Section 3 mentioned, the external capacitor $C$ appears in parallel with $C_{\mathrm{p}}$ parasitic capacitance of the terminal $p$, which value is equal to $41.12 \mathrm{fF}$. Theoretically, therefore, its total value equal to $C^{\prime} \approx 7.84 \mathrm{pF}$ should be taken into account. In Fig. 5 the ideal and simulated gain and phase responses are depicted, which are illustrating the electronic tunability of the filter. The pole frequency was varied for $f_{\mathrm{p}} \cong\{1 ; 2.96 ; 10.08\} \mathrm{MHz}$ via the bias current $I_{\mathrm{B}}=\{4$; $13 ; 63\} \mu \mathrm{A}$, respectively. The dependence of the pole frequency $f_{\mathrm{p}}$ on the bias current $I_{\mathrm{B}}$ and subsequently change of TPD are illustrated in Figs. 6 and 7, respectively. Note that in both simulations the bias current $I_{B}$ was tuned in range $3 \mu \mathrm{A}$ and $233 \mu \mathrm{A}$ which results easy tuning of the filter's pole frequency in range $763 \mathrm{kHz}$ to $17.6 \mathrm{MHz}$ and the TPD of the CM APF changes in range $\{221 \rightarrow 828\} \mu \mathrm{W}$. The effect of temperature 


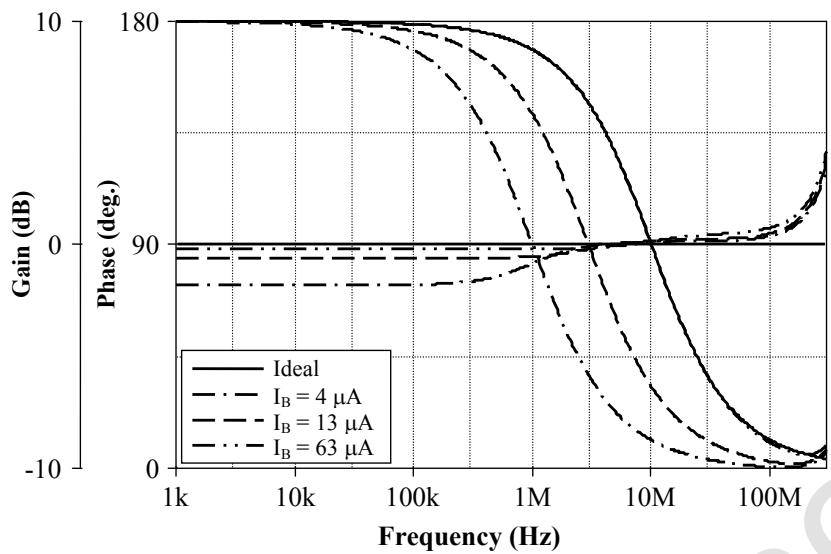

Fig. 5. Ideal and simulated gain and phase responses of the CM APF: demonstration of tunability of the $f_{\mathrm{p}}$ by the bias current $I_{\mathrm{B}}$.

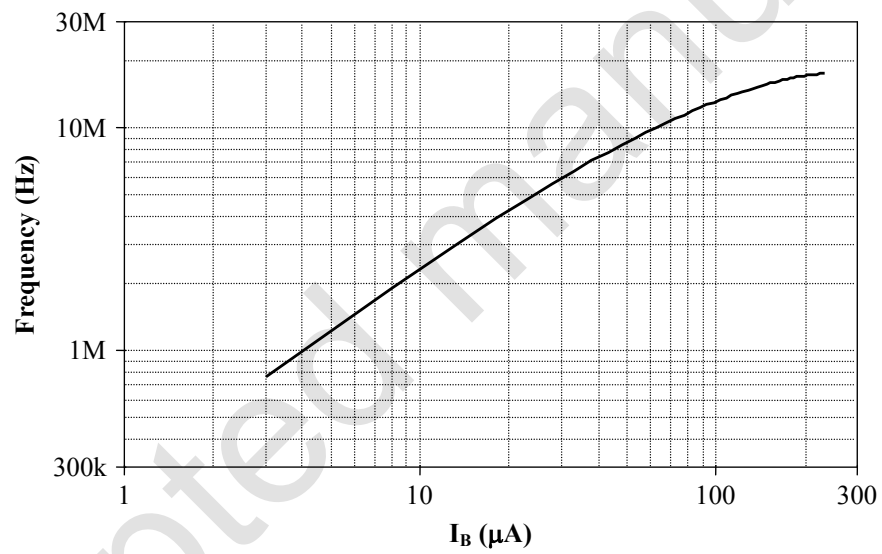

Fig. 6. Tuning the pole frequency $f_{\mathrm{p}}$ of the CM APF via bias current $I_{\mathrm{B}}$.

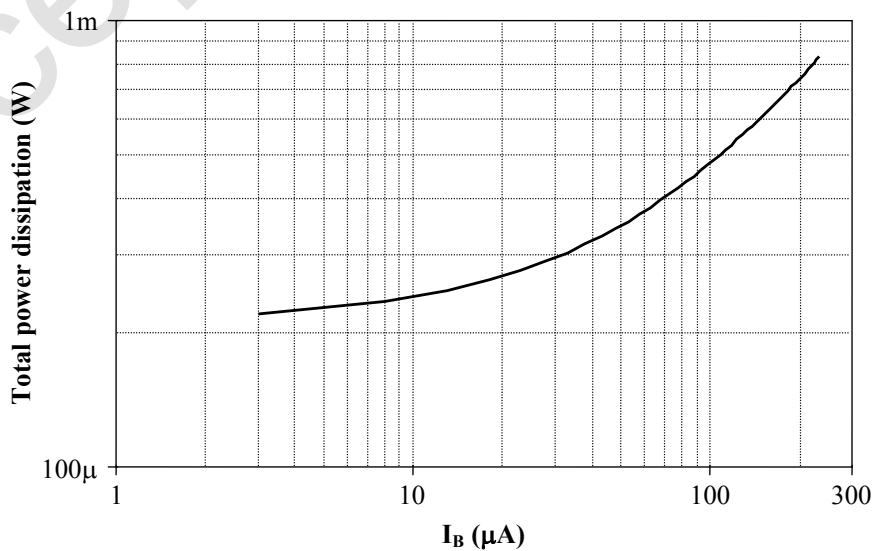

Fig. 7. Total power dissipation of the CM APF during pole frequency $f_{\mathrm{p}}$ tuning via bias current $I_{\mathrm{B}}$. 


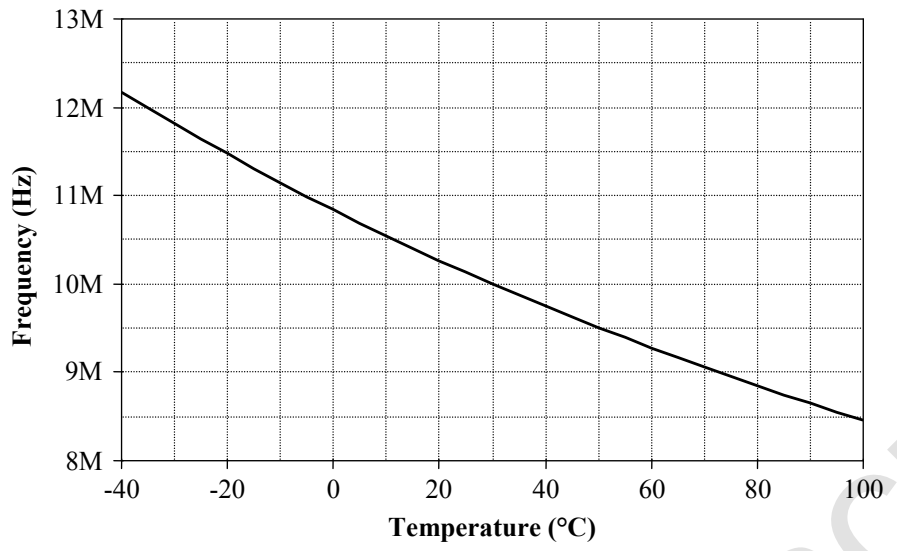

Fig. 8. Temperature dependence of pole frequency with initial settings of bias current $I_{\mathrm{B}}=63 \mu \mathrm{A}$ $\left(f_{\mathrm{p}}=10.08 \mathrm{MHz}\right)$.

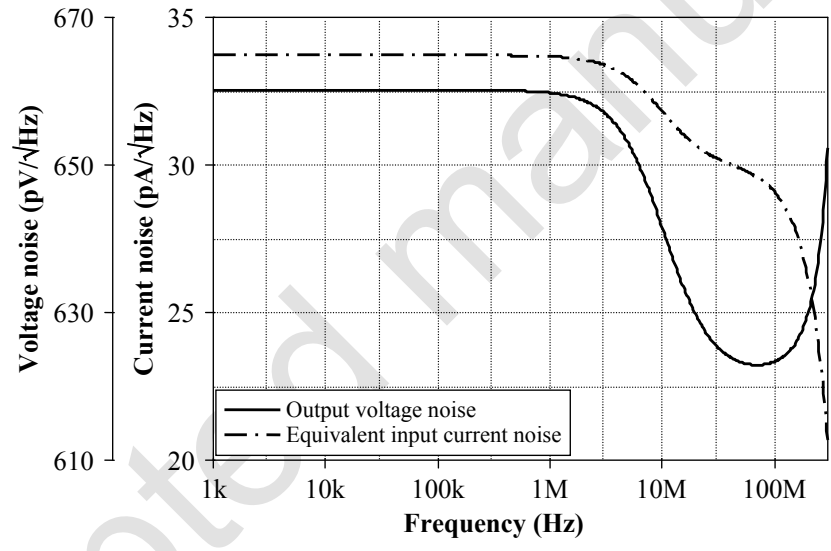

Fig. 9. Output and equivalent input noise variations vs. frequency.

on phase response of the proposed CM APF designed for $f_{\mathrm{p}}=10.08 \mathrm{MHz}\left(I_{\mathrm{B}}=63 \mu \mathrm{A}\right)$ was examined in range $T \in\{-40 ;+100\}^{\circ} \mathrm{C}$ in Fig. 8. Using the ONOISE and INOISE statements, the output and equivalent input noise variations against frequency are shown in Fig. 9, where at the output of the filter $20 \Omega$ resistor was connected to simulate the effect of the current. The computed output/input noises at operating frequency $\left(f_{\mathrm{p}} \cong 10.08 \mathrm{MHz}\right.$ ) were found as $641.3 \mathrm{pV} / \sqrt{\mathrm{Hz}}$ and $31.82 \mathrm{pA} / \sqrt{\mathrm{Hz}}$, respectively.

In order to illustrate the time-domain performance, the current swing capability, phase error of the filter, and transient analysis were evaluated as it is demonstrated in Fig. 10 while keeping the filter settings given above (i.e. $I_{\mathrm{B}}=63 \mu \mathrm{A}$ and $C=7.8 \mathrm{pF}$ ). Note that the output waveform is close to the input one. The $+90^{\circ}$ phase shift in the output against the input at pole frequency $10.08 \mathrm{MHz}$ is illustrated by the Lissajous pattern shown in Fig. 11. Figure 12 shows the frequency spectrum of the output 


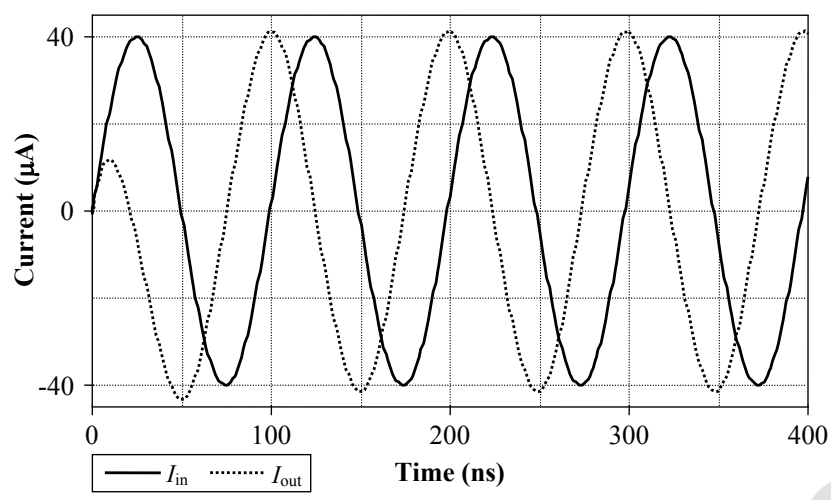

Fig. 10. Time-domain response of the proposed filter at $10.08 \mathrm{MHz}$.

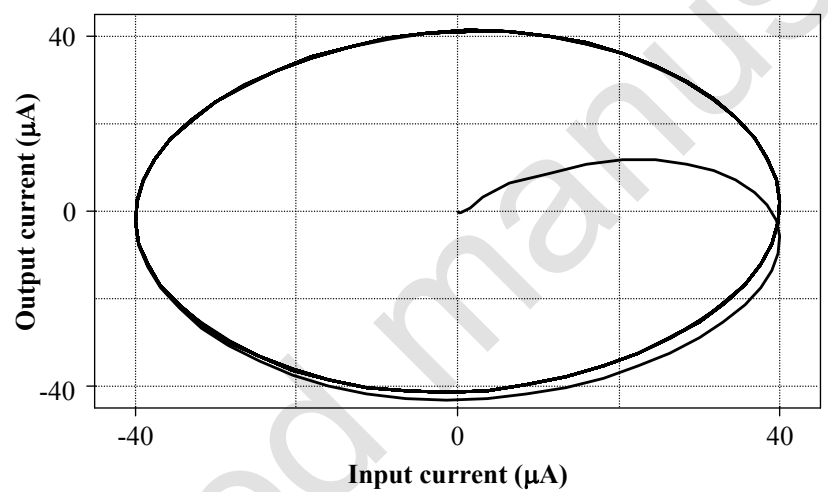

Fig. 11. Lissajous pattern showing $+90^{\circ}$ phase shift of output current against input current at $10.08 \mathrm{MHz}$.

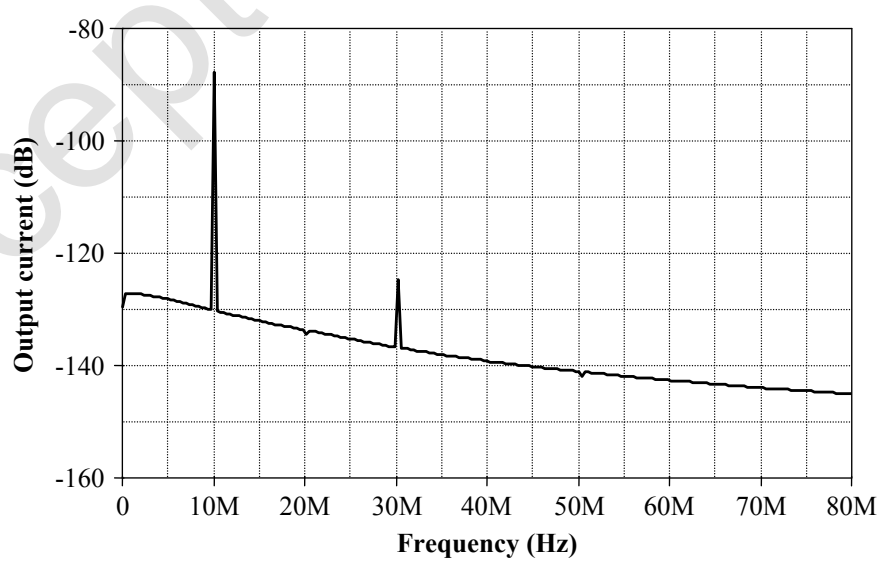

Fig. 12. Simulated frequency spectrum of the output 


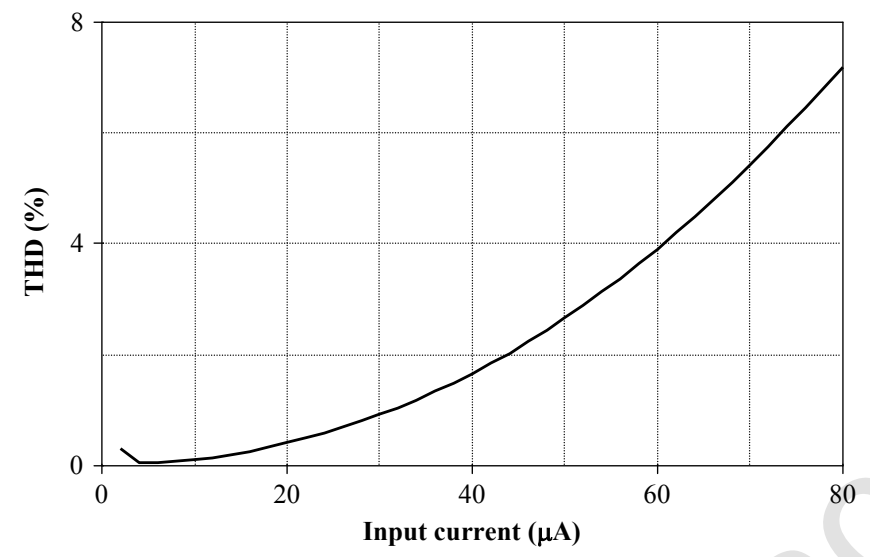

Fig. 13. THD variation of the proposed the CM APF against applied input current at $10.08 \mathrm{MHz}$.

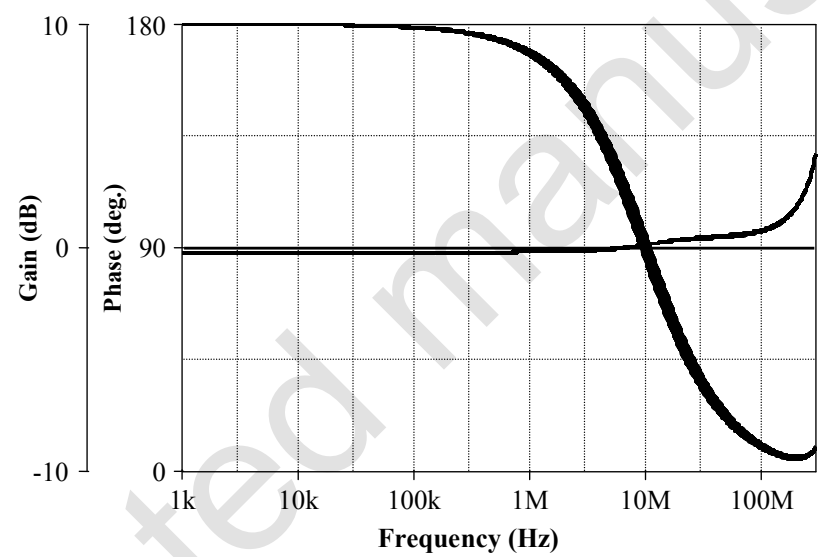

Fig. 14. Monte Carlo analysis: Simulated gain and phase response changes due to variation of the capacitor value.

waveform. The total harmonic distortion (THD) variations with respect to amplitude of the applied sinusoidal input current at $10.08 \mathrm{MHz}$ are depicted in Fig. 13. For example, an input with the amplitude of $40 \mu \mathrm{A}$ yields THD value of $1.66 \%$.

As it is well known, since parameters of electronic devices vary due to tolerances incurred from manufacturing processes, obtained results can be affected. To observe these variations and their affect, Monte Carlo (statistical) analysis is performed for capacitor with $10 \%$ tolerance and 200 runs. Fig. 14 shows the simulated gain and phase responses of the proposed CM APF. The histogram graphics in Figs. 15 and 16 demonstrate the variation of the gain of the APF at $10.08 \mathrm{MHz}$ and the variation of the filter's pole frequency, respectively.

From simulation results it can be observed that the computed SPICE simulation results using the newly designed low-voltage CBTA implementation are in very good agreement with theory. 


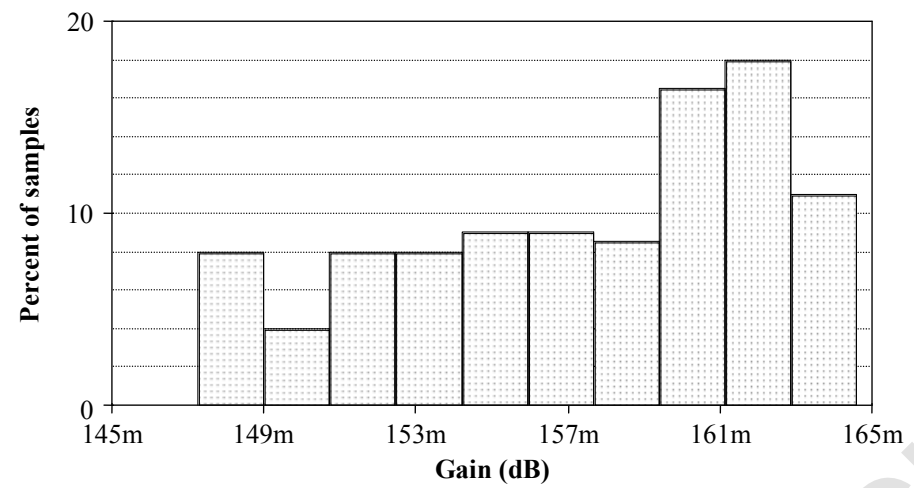

\begin{tabular}{|llll|}
$\mathrm{n}$ samples & $=200$ & 10th $\%$ ile & $=0.149877$ \\
$\mathrm{n}$ divisions & $=10$ & median & $=0.158507$ \\
mean & $=0.157374$ & 90 th $\%$ ile & $=0.163381$ \\
sigma & $=0.00488504$ & maximum & $=0.164606$ \\
minimum & $=0.147267$ & $3 *$ sigma & $=0.0146551$ \\
\hline
\end{tabular}

Fig. 15. Monte Carlo analysis: Variations of the gain of the CM APF at $10.08 \mathrm{MHz}$.

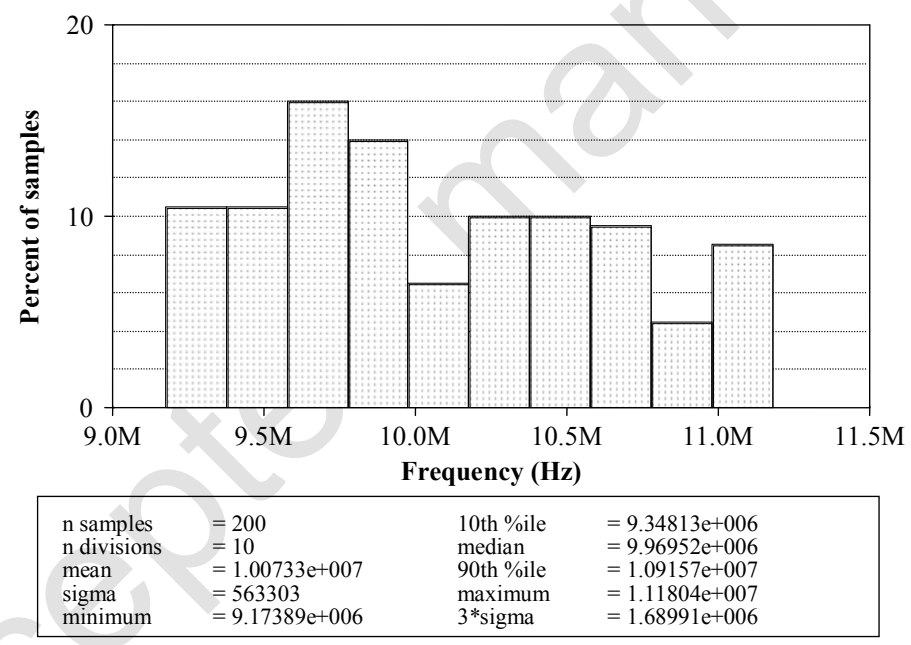

Fig. 16. Monte Carlo analysis: Variations of the pole frequency of the CM APF.

\subsection{Performance comparison}

Table 3 summarizes a fair performance comparison of proposed CM APF shown in Fig. 3 to state-of-the-art CM APFs with desired features (i)-(vi) based on relevant criterion. In order to provide overall performance evaluation, a numeric Figure of Merit (FoM) value was calculated as:

$$
\text { FoM }=\frac{V_{\text {sup }}}{\text { Area } \cdot\left(V / I_{\text {control } / \text { bias }}\right)}, \quad\left[\frac{V}{n m^{2}}\right]
$$


$16 \quad$ N. Herencsar et al.

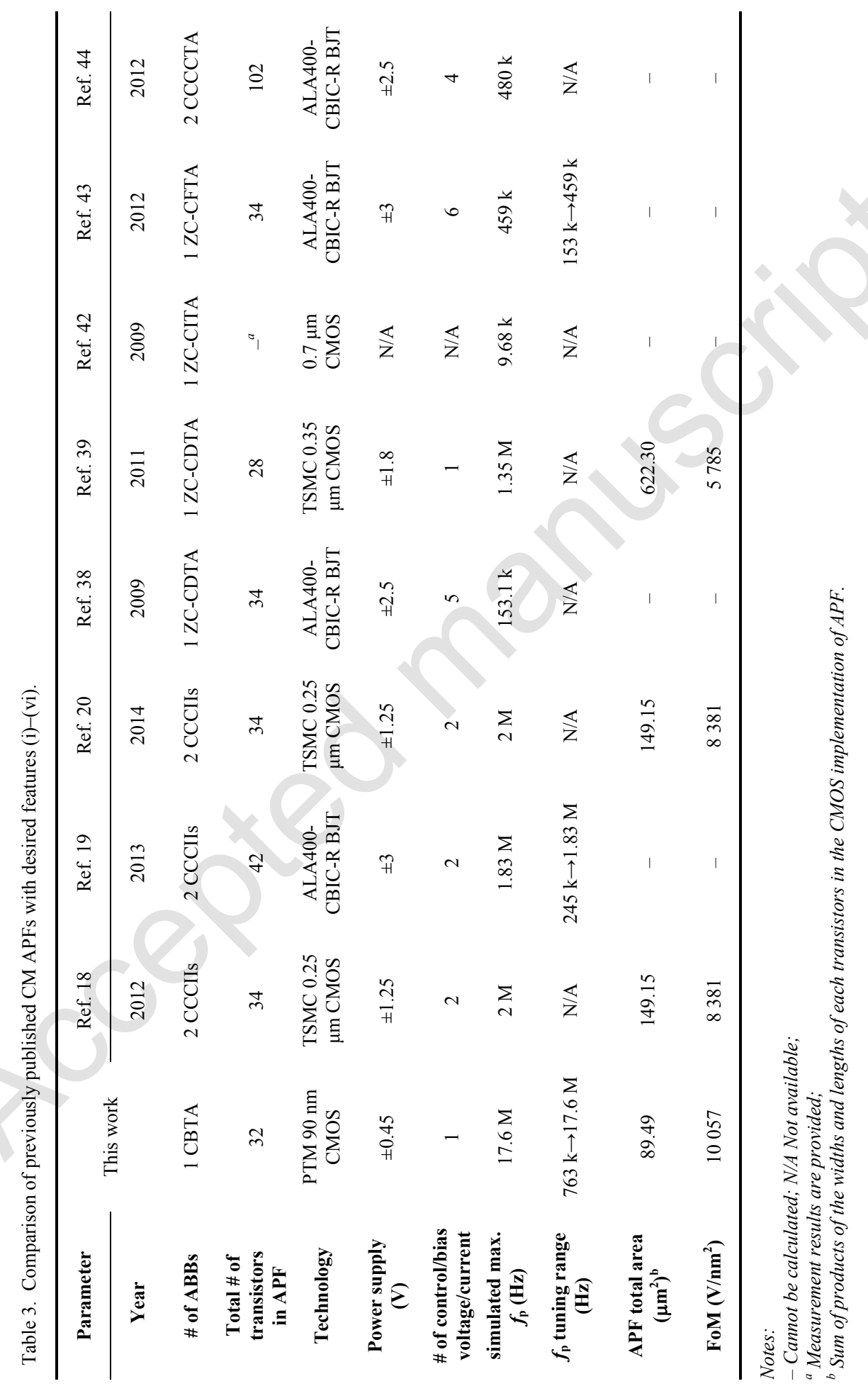




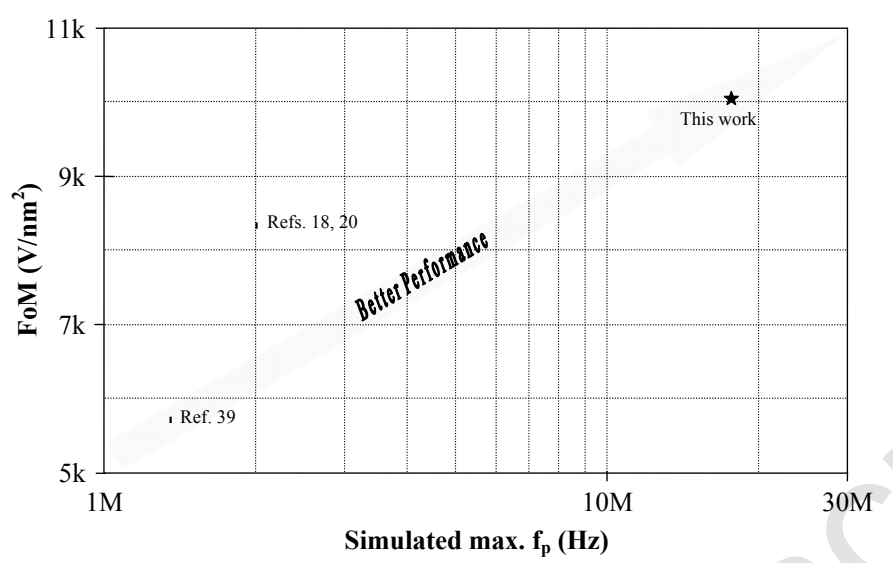

Figure 17. Figure of Merit: Performance comparison of the most appropriate CM APFs in the literature listed in Table 3.

where $V_{\text {sup }}$ stands for the power supply voltages, Area denotes APF total area, i.e. sum of products of the widths and lengths of each transistors in the CMOS implementation of $\mathrm{APF}$, and $V / I_{\text {control/bias }}$ is the number of control/bias voltage/currents, respectively. The calculated FoMs are listed in Table 3 and the results versus simulated maximum pole frequency of APF in corresponding reference are depicted in Fig. 17. Note that due to limited information in some of the listed references the FoM is calculated and compared only for CM APFs in Refs. 18, 20, and 39. Here it is worth noting that the FoM of our proposed circuit was 10 057, which is the highest value and improvement of about $20 \%$ against the highest FoM values of state-of-the-art circuits ${ }^{18,20}$ at significantly higher simulated $f_{\mathrm{p}}$.

\section{Conclusion}

In this paper, the versatility of the CBTA has been demonstrated in designing a CM firstorder all-pass filter that offers advantages such as: low impedance character of input terminal (needed for easy cascading), high output-impedance character (required for direct load connection), use of grounded capacitor (desirable for monolithic integration), no use of external resistor, i.e. circuit is resistorless, easy electronic tuning of pole frequency over more than one decade by means of external bias current, no passive and/or active matching constraints are required, and good sensitivity behavior. The performance of proposed CBTA-C APF circuit was fairly compared in details with hitherto proposed state-of-the-art circuits having desired features (i)-(vi) based on relevant criterions in Table 3. As a conclusion, above listed features and its overall performance given in Table 3, i.e. circuit is supplied with the lowest voltage, designed at the highest $f_{\mathrm{p}}$, electronic tuning of $f_{\mathrm{p}}$ over one decade, its total area is the smallest, improvement about 20\% against the highest FoM value, make the here proposed CBTAC APF circuit by far the most appropriate CM first-order APF in the current literature. 


\section{Acknowledgments}

Research described in this paper was financed by the Czech Science Foundation under grant no. 16-11460Y.

Authors wish to thank the anonymous reviewers for their useful and constructive comments that helped to improve the paper. A preliminary version of this paper has been presented at the 2016 IEEE 59th International Midwest Symposium on Circuits and Systems (MWSCAS) ${ }^{56}$.

\section{References}

1. J. E. B. Ponsonby, Active all-pass filter using a differential operational amplifier, Electronics Letters 2 (1966) 134-135, doi:10.1049/el:19660107.

2. W. Tangsrirat, On the realization of first-order current-mode AP/HP filter, Radioengineering 22 (2013) 1007-1015.

3. L. Safari, S. Minaei, E. Yuce, CMOS first-order current-mode all-pass filter with electronic tuning capability and its applications," Journal of Circuits, Systems and Computers 22 (2013) ID 1350007, 17 pages, doi:10.1142/S0218126613500072.

4. N. Herencsar, J. Jerabek, J. Koton, K. Vrba, S. Minaei, I C. Goknar, Pole frequency and passband gain tunable novel fully-differential current-mode all-pass filter, Proc. of 2015 IEEE International Symposium on Circuits and Systems (ISCAS), Lisbon, Portugal, 2015, pp. 2668 2671, doi:10.1109/ISCAS.2015.7169235.

5. E. Yuce, S. Minaei, N. Herencsar, J. Koton, Realization of first-order current-mode filters with low number of MOS transistors, Journal of Circuits, Systems, and Computers 22 (2013) 1-14, doi:10.1142/S0218126612500715.

6. M. Higashimura, Y. Fukui, Realization of current-mode all-pass networks using a current conveyor, IEEE Trans. Circuits and Systems 37 (1990) 660-661, doi:10.1109/31.55015.

7. J. W. Horng, C. L. Hou, C. M. Chang, W. Y. Chung, H. L. Liu, C. T. Lin, High-output impedance current-mode first-order allpass networks with four grounded components and two CCIIs, Int. Journal of Electronics 93 (2006) 613-621, doi:10.1080/00207210600711580.

8. M. Un, F. Kacar, New second generation current conveyor-based current-mode first order allpass filter and quadrature oscillator, J. of Istanbul Commerce University 6 (2007) 119-127.

9. E. Yuce, S. Minaei, A first-order fully cascadable current-mode universal filter composed of dual output CCIIs and a grounded capacitor, Journal of Circuits, Systems and Computers 25 (2016) ID 1650042, 15 pages, doi:10.1142/S0218126616500420.

10. S. Minaei, E. Yuce, All grounded passive elements current-mode all-pass filter, Journal of Circuits, Systems and Computers 18 (2009) 31-43, doi:10.1142/S0218126609004909.

11. J. Horng, C. Hou, Y. Guo, C. Hsu, D. Yang, M. Ho, Low input and high output impedances current-mode first-order allpass filter employing grounded passive components, Circuits and Systems 3 (2012) 176-179, doi:10.4236/cs.2012.32023.

12. I. A. Khan, P. Beg, M. T. Ahmed, First order current mode filters and multiphase sinusoidal oscillators using CMOS MOCCIIs, The Arabian Journal for Science and Engineering 32 (2007) 119-126.

13. M. Kumngern, P. Sampattavanich, P. Prommee, K. Dejhan, A capacitor-grounded currenttunable current mode all-pass network, Proc. IEEE Region 10 Int. Conf. TENCON 2004, Chiang Mai, Thailand, 2004, pp. 384-386, doi:10.1109/TENCON.2004.1414950.

14. S. Maheshwari, New voltage and current-mode APS using current controlled conveyor, Int. Journal of Electronics 91 (2004) 735-743, doi:10.1080/00207210412331332880. 
15. S. Tongkulboriboon, P. Pawarangkoon, W. Petchakit, W. Kiranon, Electronically current mode all-pass filter with only one grounded capacitor, Proc. of IEEE Region 10 Int. Conf. TENCON 2005, Melbourne, Australia, 2005, pp. 1-6, doi:10.1109/TENCON.2005.300918.

16. S. Maheshwari, A new current-mode current-controlled all-pass section, Journal of Circuits, Systems and Computers 16 (2007) 181-189, doi:10.1142/S0218126607003599.

17. S. Oztayfun, S. Kilinc, A. Celebi, U. Cam, A new electronically tunable phase shifter employing current-controlled current conveyors, AEU - Int. Journal of Electronics and Communications 62 (2008) 228-231, doi:10.1016/j.aeue.2007.03.012.

18. S. Songkla, W. Jaikla, Realization of electronically tunable current-mode first-order allpass filter and its application, Int. Journal of Electronics and Electrical Engineering 6 (2012) 4043.

19. W. Tangsrirat, Cascadable current-mode first-order allpass filter using current controlled conveyors, Przeglad Elektrotechniczny 89 (2013) 187-190.

20. P. B. Petrovic, A new tunable current-mode peak detector, Microelectronics Journal 45 (2014) 805-814, doi:10.1016/j.mejo.2014.02.019.

21. J. Mohan, S. Maheshwari, Cascadable current-mode first-order all-pass filter based on minimal components, The Scientific World Journal 2013 (2013) Article ID 8597845 pages, doi: $10.1155 / 2013 / 859784$.

22. J. Mohan, Single active element based current-mode all-pass filter, Int. Journal of Computer Applications 82 (2013) 23-27.

23. S. Maheshwari, I. A. Khan, Novel first-order current-mode allpass sections using CCIII, Active and Passive Electronic Components 27 (2004) 111-117, doi:10.1080/08827510310001616803.

24. M. Un, F. Kacar, Third generation current conveyor based current-mode first order all-pass filter and quadrature oscillator, IU-Journal of Electrical \& Electronics Eng. 8 (2008) 529-535.

25. N. Herencsar, J. Koton, K. Vrba, O. Cicekoglu, New current-mode all-pass filter with grounded capacitor based on gain-variable CCIII, Proc. of 11th Int. IEEE Region 8 AFRICON 2013, Pointe-Aux-Piments, Mauritius, 2013, pp. 559-562, doi:10.1109/AFRCON.2013.6757657.

26. S. Minaei, M. A. Ibrahim, General configuration for realizing current-mode first-order all-pass filter using DVCC, Int. Journal of Electronics 92 (2005) 347-356, doi:10.1080/00207210412331334798.

27. F. Kacar, M. Un, DVCC based current-mode first order all-pass filter and quadrature oscillator, Trakya Univ Journal of Science 8 (2007) 1-5.

28. M. Higashimura, Current-mode allpass filter using FTFN with grounded capacitor, Electronics Letters 27 (1991) 1182-1183, doi:10.1049/el:19910737.

29. N. Herencsar, J. Koton, A. Lahiri, B. Metin, K. Vrba, A voltage gain-controlled modified CFOA and its application in electronically tunable four-mode all-pass filter design, International Journal of Advances in Telecommunications, Electrotechnics, Signals and Systems 1 (2012) 20-25, doi:10.11601/ijates.v1i1.27.

30. B. Metin, K. Pal, S. Minaei, O. Cicekoglu, Trade-offs in the OTA-based analog filter design, Analog Integrated Circuits and Signal Processing 60 (2009) 205-213, doi:10.1007/s10470008-9270-x.

31. C. Psychalinos, K. Pal, A novel all-pass current-mode filter realized using a minimum number of single output OTAs, Frequenz 64 (2010) 30-32, doi:10.1515/FREQ.2010.64.1-2.30.

32. A. Toker, S. Ozoguz, O. Cicekoglu, C. Acar, Current-mode allpass filters using current differencing buffered amplifier and a new high-Q bandpass filter configuration, IEEE Trans. Circuits and Systems-II 47 (2000) 949-954, doi:10.1109/82.868465. 
33. S. Kilinc, U. Cam, Current-mode first-order allpass filter employing single current operational amplifier, Analog Integrated Circuits and Signal Processing 41 (2004) 47-53, doi:10.1023/B:ALOG.0000038282.60137.5f.

34. A. U. Keskin, D. Biolek, Current mode quadrature oscillator using current differencing transconductance amplifiers (CDTA), IEE Proc.-Circuits, Devices and Systems 153 (2006) 214-218, doi:10.1049/ip-cds:20050304.

35. A. Uygur, H. Kuntman, Low-voltage current differencing transconductance amplifier in a novel allpass configuration, Proc. 13th Conf. MELECON 2006, Malaga, Spain, 2006, pp. $23-$ 26, doi:10.1109/MELCON.2006.1653026.

36. W. Tanjaroen, W. Tangsrirat, Resistorless current-mode first-order allpass filter using CDTAs, Proc. 5th Int. Conf. ECTI-CON 2008, Krabi, Thailand, 2008, pp. 721-724, doi:10.1109/ECTICON.2008.4600532.

37. W. Tangsrirat, T. Pukkalanun, W. Surakampontorn, Resistorless realization of current-mode first-order allpass filter using current differencing transconductance amplifiers, Microelectronics Journal 41 (2010) 178-183, doi:10.1016/j.mejo.2010.02.001.

38. A. Lahiri, A. Chowdhury, A novel first-order current-mode all-pass filter using CDTA, Radioengineering 18 (2009) 300-305.

39. N. Pandey, S. K. Paul, Single CDTA-based current mode all-pass filter and its applications, Journal of Electrical and Computer Engineering 2011 (2011) Article ID 897631, 5 pages, doi:10.1155/2011/897631.

40. E. Tlelo-Cuautle, L. G. De La Fraga, K. Phanrattanachai, K. Pitaksuttayaprot, CDCTA and OTA realizations of a multi-phase sinusoidal oscillator, IETE Technical Review 32 (2015) 497-504, doi:10.1080/02564602.2015.1043149.

41. R. Sotner, J. Jerabek, N. Herencsar, T. Zak, W. Jaikla, K. Vrba, Modified current differencing unit and its application for electronically reconfigurable simple first-order transfer function, Advances in Electrical and Computer Engineering 15 (2015) 3-10, doi:10.4316/AECE.2015.01001.

42. D. Biolek, V. Biolkova, Allpass filter employing one grounded capacitor and one active element, Electronics Letters 45 (2009) 807-808, doi:10.1049/el.2009.0575.

43. W. Tangsrirat, P. Mongkolwai, T. Pukkalanun, Current-mode high-Q bandpass filter and mixed-mode quadrature oscillator using ZC-CFTAs and grounded capacitors, Indian Journal of Pure \& Applied Physics 50 (2012) 600-607.

44. W. Jaikla, A. Noppakarn, S. Lawanwisut, New gain controllable resistor-less current-mode first order allpass filter and its application, Radioengineering 21 (2012) 312-316.

45. N. Herencsar, J. Koton, K. Vrba, Electronically tunable phase shifter employing currentcontrolled current follower transconductance amplifiers (CCCFTAs), Proc. 32th Int. Conf. TSP 2009, Dunakiliti, Hungary, 2009, pp. 54-57.

46. U. E. Ayten, M. Sagbas, S. Minaei, Realization of low-voltage modified CBTA and design of cascadable current-mode all-pass filter, Radioengineering 23 (2014) 523-531.

47. U. E. Ayten, M. Sagbas, H. Sedef, Current mode leapfrog ladder filters using a new active block, AEU - Int. Journal of Electronics and Communications 64 (2010) 503-511, doi:10.1016/j.aeue.2009.03.012.

48. M. Sagbas, U. E. Ayten, H. Sedef, Current and voltage transfer function filters using a single active device, IET Circuits, Devices \& Systems 4 (2010) 78-86, doi:10.1049/ietcds.2009.0121.

49. M. Sagbas, Component reduced floating $\pm \mathrm{L}, \pm \mathrm{C}$ and $\pm \mathrm{R}$ simulators with grounded passive components, AEU - Int. Journal of Electronics and Communications 65, no. 10) 794-798, 2011, doi:10.1016/j.aeue.2011.01.006.

50. U. E. Ayten, M. Sagbas, N. Herencsar, J. Koton, Novel floating general element simulators using CBTA, Radioengineering 21 (2012) 11-19. 
51. M. Sagbas, M. Koksal, Realization of a general resistorless active biquad using CBTA, Journal of Circuits, Systems, and Computers 21 (2012) ID 1250013, 12 pages, doi:10.1142/S0218126612500132.

52. M. Koksal, Realization of a general all-pole current transfer function by using CBTA, International Journal of Circuit Theory and Applications 41 (2013) 319-329, doi:10.1002/cta.806.

53. M. Sagbas, U. E. Ayten, N. Herencsar, S. Minaei, Current and voltage mode multiphase sinusoidal oscillators using CBTAs, Radioengineering 22 (2013) 24-33.

54. M. Sagbas, U. E. Ayten, H. Sedef, S. Minaei, Modified gorski-popiel technique and synthetic floating transformer circuit using minimum components, Journal of Circuits, Systems, and Computers 26 (2017) 1-21, doi:10.1142/S021812661750013X.

55. PTM $90 \mathrm{~nm}$ CMOS technology SPICE BSIM3v3 parameters [online]: http://bwrcs.eecs.berkeley.edu/Classes/icdesign/ee241_s07/Assignments/90nm_bulk.txt

56. N. Herencsar, J. Koton, M. Sagbas, U. E. Ayten, New tunable resistorless CM first-order filter based on single CBTA and grounded capacitor, Proc. of the 2016 IEEE 59th International Midwest Symposium on Circuits and Systems (MWSCAS), Abu Dhabi, United Arab Emirates, 2016, pp. 501-504, doi:10.1109/MWSCAS.2016.7870064. 